\title{
AGRICULTURAL ACTIVITIES OF THE MALAYALI TRIBAL FOR SUBSISTENCE AND ECONOMIC NEEDS IN THE MID ELEVATION FOREST OF PACHAMALAI HILLS, EASTERN GHATS, TAMIL NADU
}

\author{
V. Anburaja* and V. Nandagopalan
}

Received 26 December 2011, Revised 1 March 2012, Accepted 15 June 2012, Published online 30 June 2012

\begin{abstract}
This paper is aimed to study the Agricultural activities of the Malayali Tribal for Subsistence and Economic needs in the mid elevation forest of Pachamalai Hills, Eastern Ghats, Tamil nadu. About 8 percent of the Indian population belongs to a category listed as "Scheduled Tribes" enumerated in the Schedule to Article 342 of the Constitution of India. Tribal people has been seen to be strongly associated with the forests, hills and remote areas, practicing a unique life style, having a unique set of cultural and religious beliefs. For millennia, tribal communities have lived in forests and survived on hunting and gathering. However, with growing population and resource pressure, it is now witnessing that a rise in livelihoods based on settled farming. In the study area, cereals are the major crop cultivated for their edible grains. The tribal people living in the hills tops of the study area were cultivated 11 major agricultural crops. They are, Eleusine coracana, Panicum miliare, Oryza sativa (verity I) (Mara Nellu), Oryza sativa (verity II), Manihot esculenta, Macrotyloma uniflorum, Vigna mungo, Sesamum orientale, Paspalum sp, Pennisetum americanum and Setaria italica. Among them, Paspalum sp gives the maximum yield with $655 \mathrm{~kg} \mathrm{acre}^{-1}$.
\end{abstract}

Keywords: Agricultural Activities, Malayali Tribal, Mid Elevation Forest, Pachamalai Hills, Tamil Nadu

PG and Research Department of Botany, National College, Tiruchirappalli - 620 001, Tamil Nadu, India.

*Corresponding author's email: vanburaja@gmail.com (V. Anburaja)

Reviewed by Md. Rahsedur Rahman, Bangladesh Agricutural University, Mymensingh, Bangladesh.

\section{Introduction}

Today, India ranks second worldwide in farm output. Agriculture and allied sectors like forestry and logging accounted for $16.6 \%$ of the GDP in 2007, employed $60 \%$ of the total workforce (CIA, 2008) and despite a steady decline of its share in the GDP, is still the largest economic sector and plays a significant role in the overall socioeconomic development of India. The population of India is 1.2 billion. Simultaneously, farmland is expected to be engulfed by urbanization and environmental degradation. To maintain a satisfactory food security system, crop production should increase by $3 \%$ a year (Ravishankar and Selvam, 1996).

The tribal population in India is 84.51 million, which constitutes $8.14 \%$ of tribal population (Census, 2001). There are about 449 tribes and sub tribes in different parts of India. Half of the India's tribal people live in the forests and forest fringes and their economy is link with the forests. Most of the tribals in Tamilnadu are cultivators, cattle rearing agriculture laborers or dependent on forests of their livelihood. In Tamilnadu 36 scheduled tribe communities have been identified
(Source: Tamilnadu Forest Department Web site: http:// www.forests.tn.nic.in).

Tribal communities, namely Irulas, Malayalis and Muthuvans living in the state of Tamil Nadu, have been cultivating traditional cultivars of paddy, millets, pulses and vegetables. The traditional cultivars sown by them, over generations, form the principal crops of their agricultural system (Ravishankar and Selvam, 1996). The subsistence life style, local diet habits and organoleptic preferences of these tribes, as well as their dependence on monsoon rain for irrigation, have led them to cultivate and conserve local seeds for consumption and for sowing the following season. This traditional practice is a blessing in disguise and has saved many forms of specific and intra-specific varieties of millets and paddy. Historically, the economy of most tribes was subsistence agriculture or hunting and gathering. Tribal members traded with outsiders for the few necessities they lacked, such as salt and iron (Thakur and Sunil Pandey, 2009) 
Their knowledge of seed selection, their traditional methods of conserving seeds and grains in eco-friendly traditional granaries and their communities' participation in maintaining germplasm and plant protection methods provide important insights to global efforts aimed at genetic conservation (Ravishankar and Selvam, 1996).

Shifting cultivation is an agricultural system in which plots of land are cultivated temporarily, and then abandoned. This system often involves clearing of a piece of land followed by several years of wood harvesting or farming, until the soil loses fertility. Once the land becomes inadequate for crop production, it is left to be reclaimed by natural vegetation, or sometimes converted to a different long-term cyclical farming practice. In addition, ecological consequences are often deleterious, but can partially mitigate if new forests are not invaded (Anderson, 1997).

Shifting cultivation has resulted in large-scale deforestation, soil and nutrient loss, and invasion by weeds and other species. The indigenous biodiversity has affected largely. Shifting cultivation is prevalent mostly in tropical countries. In India, the people of eastern and north-eastern region practice shifting cultivation on hill slopes. $85 \%$ of the total cultivation in northeast India is by shifting cultivation (Singh and Singh, 1992). Due to increasing requirement for cultivation of land, cycle of cultivation followed by leaving land fallow has reduced from $25-30$ years to 2- 3 years. Earlier the fallow cycle was of 20 - 30 years duration, thereby permitting the land to return to natural condition (Patro and Panda, 1994). Due to reduction of cycle to 2-3 years, the resilience of ecosystem has broken down and the land is increasingly deteriorating. The paper discusses the shifting-cultivation practices in the eastern and northeastern regions of the country, and suggests certain strategies to revive the deforested areas for achieving ecological sustainability Agricultural practices are at the cost of loss of biodiversity resources; estimates indicate that one unit of energy in agronomic production costs loss of greater energy from the forests. However, in the Central Himalayan eco-systems, where agriculture practice is more scientific compared to shifting cultivation, one unit of energy in agronomic production entails an expenditure of about 10-12 units of energy from the surrounding forests as firewood, fodder and leaf manure (Singh, 1986). Loss of energy from the forests per unit of agricultural production may be far greater in shifting-cultivation areas. Agricultural practices are at the cost of loss of biodiversity resources; estimates indicate that one unit of energy in agronomic production costs loss of greater energy from the forests. However, in the Central
Himalayan eco-systems, where agriculture practice is more scientific compared to shifting cultivation, one unit of energy in agronomic production entails an expenditure of about 1012 units of energy from the surrounding forests as firewood, fodder and leaf manure (Singh, 1986).

Agricultural practices are at the cost of loss of biodiversity resources; estimates indicate that one unit of energy in agronomic production costs loss of greater energy from the forests. However, in the Central Himalayan eco-systems, where agriculture practice is more scientific compared to shifting cultivation, one unit of energy in agronomic production entails an expenditure of about 10-12 units of energy from the surrounding forests as firewood, fodder and leaf manure (Singh, 1986). Loss of energy from the forests per unit of agricultural production may be far greater in shifting-cultivation areas.

The increase in human population, particularly in the developing countries, has put tremendous pressures on land. The extension of crop lands, for increasing food production, has been directly responsible for the reduction in areas under forests and grass lands. According to one estimate, about $40 \%$ of the land surface of the earth was converted into crop lands and permanent pastures by early 1990s. More than $6 \%$ area under tropical forests was converted to shifting cultivation between 1980 and 1990 across all tropical countries (World Resource Institute, 1996). This paper is aimed to study the Agricultural activities of the Malayali Tribal for Subsistence and Economic needs in the mid elevation forest of Pachamalai Hills, Eastern Ghats, Tamil nadu.

\section{Materials and Methods}

The data collections were done during 20062008 to collect information on the agricultural practices of Malayali tribes in the Pachamalai hills. The above villages lie in these hills are situated at the mid regions of Tamilnadu with Latitudes $11^{\circ} 09^{\prime} 00^{\prime \prime}$ to $11^{\circ} 27^{\prime} 00^{\prime \prime} \mathrm{N}$ and longitudes $78^{\circ} 28^{\prime} 00^{\prime \prime}$ to $78^{\circ} 49^{\prime} 00^{\prime \prime} \quad \mathrm{E}$ and included to the Salem and Tiruchirappalli districts.

This study was made mainly by the interviews with the trial people of the study area. Interview was a two-way communication processes between a minimum of two persons namely a respondent and an interviewer. In the present study, interview was made between various user groups and farm hold peoples. Non-verbal responses like smile, nodding head, change in tone, eye contact were personally noted down. Such non-verbal signals have lot of hidden meaning which cannot be recorded without 
proper interception. To overcome this, probing process was adapted. The data collected from the tribal people of the study area were statistically calculated with Microsoft excel program 2007.

\section{Results and Discussion}

Their knowledge of seed selection, their traditional methods of conserving seeds and grains in eco-friendly traditional granaries and their communities' participation in maintaining germplasm and plant protection methods provide important insights to global efforts aimed at genetic conservation. By care full selection and conservation, these communities have enhanced the genetic potential of their seeds and have been identified from the tribal communities. The tribals prefer to continue the cultivation of their own traditional cultivars is these crops are ecologically suitable, drought resistant, pest tolerant and disease resistant.

Mostly the hills top land was used the cultivation of 11 agricultural crops. Among them, Eleusine coracana gave $8 \%$, Panicum miliare gave $12 \%$, Oryza sativa (verity I) (Mara Nellu) gave $9 \%$ and Oryza sativa (verity II) gave $11 \%$, totally $20 \%$, the productivity of Manihot esculenta was $16 \%$, Macrotyloma uniflorum 2\%, Vigna mungo 3\% of the total productivity of the uphill crops. Sesamum orientale supplies the edible oil need with the $11 \%$ of total productivity, Paspalum sp give maximum yield with $17 \%$ of the total productivity i.e., $655 \mathrm{~kg}$ acre-1. Pennisetum americanum and Setaria italica gave 6\% and 5\% of the productivity respectively (Table 1). During the agricultural process, the native flora of forest was disturbed and devasted from parental lands. The present study have also observed the low rainfall concomitantly with increasing temperature on hills tops has caused the shifting of agricultural land have lead to the damaged species distribution pattern in natural ecosystem which indirectly has affected the ecosystem functioning.

In case land, cultivated for a long time, it is highly probable that the land may turn infertile. This is due to lack of organic matter and minerals rich in nitrogen and phosphorus. The land may turn acidic and lose its percolation capacity. After some period of cultivation, the land would be left as it lacks the minerals and organic matter for the growth of the crop plants. According to the view of some environmental scientists, the system of shifting cultivation is an unproductive and wasteful process of cultivation. They also opine that shifting cultivation is the prime cause for widespread environmental degradation and destruction of tropical forests in the world. In a stable shifting cultivation system, the fallow land is used for natural vegetation for a longer period of time, to regain the fertility of the soil. If the fallow land is kept uncultivated for a longer period, it will be more fertile in nature. During this period, the soil temperature becomes lower and nutrients are extracted from the subsoil. This would also lead to the reduction in the soil acidity level.

The irrigation system of the Malayali tribes of the study area is mainly depending on the seasonal monsoon rainfall. In addition, there is no proper irrigating system in the study area except in the few villages.

\section{Animal husbandry}

Goat rearing also plays a vital role in supplying their meat and money. Cows and bullocks are maintained only for the ploughing. After the ploughing period the both the cows and bullocks are left in the village surrounding area until the next season. So the production of milk from the cows is almost nil.

Poultry - indigenous varieties of hen and cocks are maintained for egg and meat production especially in the tribal areas. Indigenous Cow and bullocks are also maintained. These are mainly for ploughing purpose. After ploughing, the cattle are simply left in the areas surrounding the tribal area until the next season.

Piggery is the most popular Animal Husbandry Venture in the tribal areas. Tribal families of the study area maintain the indigenous pigs for their meat during the festivals, marriage ceremonies and some other needed days.

\section{Recommendations}

Extension and continuous training programmes in the tribal villages to popularize Animal Husbandry as a venture for augmenting milk, meat and egg production and to increase the rural employment potential in the study area. Hybrid cows have to be supply to increase the milk production. Hybrids of goat may be given to the tribes with a training will give a additional economic support to them. Fodder seed production farm, developing grazing land, establishing Silvi Pastural System and fodder training cum extension programme as well as free supply of fodder seeds and cutting is needed in the tribal area to reduce the deforestation due to over grazing. Supplying exotic pigs to tribes and a new scheme of insurance of pigs belonging to tribals has been taken up apart from providing practical training in pig keeping.

Several factors may contribute to the persistence of their local knowledge. The lack of modern and government facilities and remote geographical features of tribal area, as well as a strong belief in folk knowledge continue the preference for traditional knowledge for their life style (Shandesh Bhattarai et al., 2006). 
Table 1. Check List of Plants Species with Agricultural Importance to Tribal Community

\begin{tabular}{|c|c|c|c|}
\hline Sl. No. & Name of the crops & Type of irrigation & Yield (Kg acre-1) \\
\hline 1. & Eleusine coracana (L.) Gaertner & $\begin{array}{l}\text { Depends on rain water. } \\
\text { (Manavari) }\end{array}$ & $309 \pm 73.74$ \\
\hline 2. & Panicum miliare Lam. & Depends on rain water & $486 \pm 74.68$ \\
\hline 3. & Oryza sativa L. (Mara Nellu) & Depends on rain water. & $334 \pm 70.01$ \\
\hline 4. & Oryza sativa L. & $\begin{array}{l}\text { Stream water (only available } \\
\text { October to February) }\end{array}$ & $417 \pm 79.97$ \\
\hline 5. & Manihot esculenta Crantz. & Depends on rain water. & $635 \pm 110.67$ \\
\hline 6. & $\begin{array}{l}\text { Macrotyloma uniflorum (Lam.) } \\
\text { Verdc. }\end{array}$ & Depends on rain water. & $82 \pm 25.88$ \\
\hline 7. & Vigna mungo (L.) Hepper. & Depends on rain water. & $100 \pm 22.78$ \\
\hline 8. & Sesamum orientale L. & Depends on rain water. & $432 \pm 74.58$ \\
\hline 9. & Paspalum sp. & Depends on rain water. & $655 \pm 83.16$ \\
\hline 10. & $\begin{array}{l}\text { Pennisetum americanum (L.) } \\
\text { Leeke }\end{array}$ & Depends on rain water. & $250 \pm 38.47$ \\
\hline 11. & Setaria italic (L.) P. Beauv. & Depends on rain water. & $181 \pm 52.95$ \\
\hline
\end{tabular}

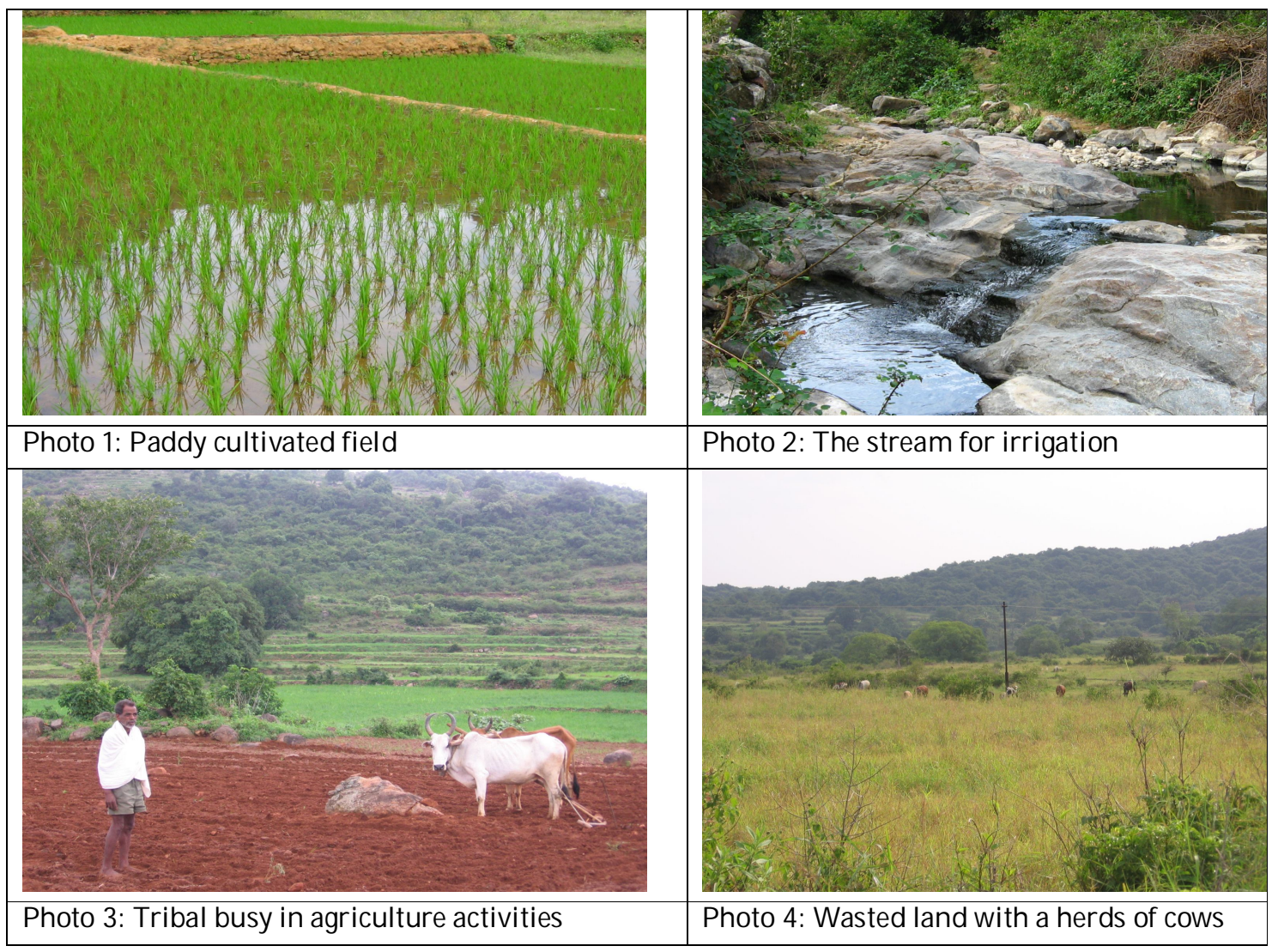

Fig. 1. Agricultural practices in the study area 


\section{References}

Anderson, A. 1997. Prehistoric Polynesian impact on the New Zealand environment: Te Whenua Hou. In Historical Ecology in the Pacific Islands: Prehistoric Environmental and Landscape Change (Eds, Kirch, P. V. and Hunt, T. L.) Yale University Press, New Haven and London. pp. 271-283.

Census. 2001 Web address: http:// tribesindia.com

CIA. 2008. CIA Fact book: India. Central Intelligence Agency. https://www.cia.gov/ library/ publications/ the-world-factbook /geos/in.html. Retrieved 2008-06-10.

Patro, S.N. and Panda, G.K. 1994. Eastern Ghats in Orissa: Environment, Resources and Development, Orissa Environment Society.

Ravishankar, T. and Selvam. V. 1996. Contributions of Tribal Communities in the Conservation of Traditional Cultivars. In: Using Diversity: Enhancing and Maintaining Genetic Resources On-farm, International
Development Research Centre, New Delhi, India. pp. 78-86.

Shandesh Bhattarai, Ram P Chaudhary and Robin S.L. Taylor. 2006. Ethnomedicinal plants used by the people of Manag district, central Nepal. J. Ethnobiology and Ethnomedicne, 2:41 (doi: 10.1186/17464269-2-41).

Singh, J.S. 1986. Eco-Development Guidelines and Model of Development of the Central Himalaya, Department of Botany, Kumaun University, Nainital. p. 48.

Singh, J.S. and Singh, S.P. 1992. Forests of Himalaya, Gyanodaya Prakashan, Naini p. 294.

Thakur, A.P. and Sunil Pandey. 2009. 21st Century India. Global vision publishing house, New Delhi. 510 p.

Web: http://www.forests.tn.nic.in

WRI. 1996. World Resource, World Resource Institute, Oxford University Press, Oxford, $365 \mathrm{p}$. 